\title{
Long-term variations of fumarole temperatures on Vulcano Island (Italy)
}

\author{
Iole Serena Diliberto
}

Istituto Nazionale di Geofisica e Vulcanologia, sezione di Palermo, Palermo, Italy

\author{
Article history \\ Received January 5, 2011; accepted May 27, 2011. \\ Subject classification: \\ Volcano monitoring, Instruments and techniques, Heat release, Geochemical data.
}

\section{ABSTRACT}

Fumarole temperatures are the ultimate results of many processes that are encountered by deep fluids during their passage to the surface. Here, the time variations of high-temperature fumaroles acquired by continuous monitoring are presented, to show the effects of the forces that act on the system. Data acquired by continuous monitoring of fumaroles and the time relationships with the different parameters related to the activity of the volcanic system are discussed. From 1998 to 2010, the temperature and compositional changes of fumarolic gases were monitored at the same time as variations in the number of volcanoseismic events, which indicate frequent variations of energy release (heat and mass flow, and seismic strain release). Geochemical modeling applied to the volcanic system of Vulcano Island suggests that the overall expansion of magmatic gas through the fractured system is an almost iso-enthalpic process at depth, which shifts to an adiabatic process at shallow depth, where the rock permeability increases. Thus, the time variations of the fumarole temperatures reflect various physical variations of the system that can either occur at depth or close to the surface. The temperature monitoring performed in the fumarolic area of La Fossa Cone showed short-term effects related to rain events, and negligible effects related to other external agents (ambient temperature and atmospheric pressure variations). At the same time, the long-term monitoring highlighted some mean-term and long-term variations. These last are the main characters observed in the time-series, and they both appear to be related to endogenous forces that perturb the equilibrium of this complex geochemical system.

\section{Introduction}

The Aeolian Islands are characterized by seismic energy release that is higher than the regional background [Montalto 1996, Mattia et al. 2008], and by active magmatism that drives the volcanic activity of Stromboli volcano and the hydrothermal activities of Panarea, Lipari and Vulcano Islands (Figure 1). The time-series of geochemical and geophysical parameters acquired at Vulcano Island allow us to follow in real time the local effects of the different forces acting in the complex geodynamic system of Southern Tyrrenium.

The fumarolic field at la Fossa Cone is fed by hydrothermal systems located beneath the Lipari-Vulcano volcanic complex. The main scopes of long-term monitoring are the evaluation of geological risks associated with the forces acting on the system, and the deterministic forecasting of the dynamics observed. In both cases, it is necessary to register the effective dynamics of any measurable variables related to the mass and energy flow, in order to verify the reliability of theoretical models.

At Vulcano Island, continuous monitoring of the temperature begun in 1984 in the framework of geochemical studies aimed at modeling the processes governing the variations observed for seismic and hydrothermal release. The time relationships between the geochemical and geophysical variations have been highlighted in previous approaches to the system [Badalamenti et al. 1986, Barberi et al. 1991, Montalto 1996]. However, fumarole temperature measurements for active volcano monitoring have not yet obtained an appropriate level of attention. Often studies dealing with this argument have expressed the need for the gathering of more data and highlighted relevant effects of external disturbances on the temperatures monitored [Badalamenti et al. 1986, Connor et al. 1993, Richter et al. 2004]. Among other sites, continuous monitoring of temperature has been carried out for three particular high-temperature fumaroles on the active cone of La Fossa (Figure 2, FA, F5, F5AT). The specific locations of these monitored sites are illustrated in Figure $2 \mathrm{~b}$. The present study deals with data from the F5AT fumarole, which among all of the monitored sites, is the fumarole vent that is most representative of deep processes, and through all the years of monitoring, it has supplied the series of data that has been the least perturbed by external agents. Data coming from other sites have been useful to verify by comparison the general characters of some of the variations recorded, as well as occasional external disturbances that have been caused by either technical failures or dramatic changes in atmospheric pressure and temperature. In the present study, a few examples of time-series from the other fumaroles are included.

The high temperatures of the fumaroles of the La Fossa cone should reflect the thermal equilibrium between high- 


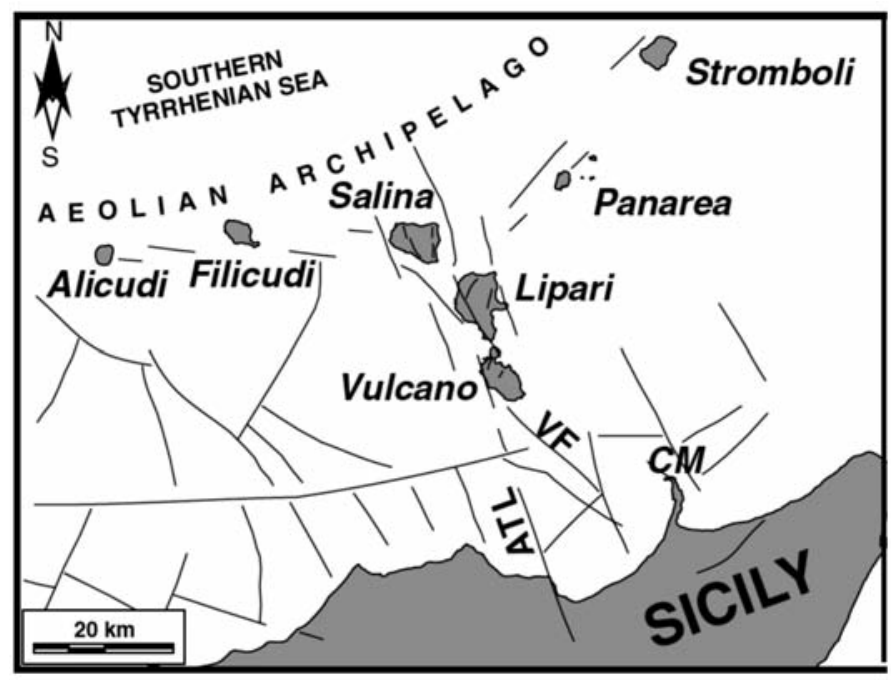

Figure 1. Structural sketch map of the Aeolian archipelago, redrawn from Mattia et al. [2008]. ATL, Aeolian-Tindari-Letojanni fault system; VF, Vulcano Fold, CM Capo Milazzo.
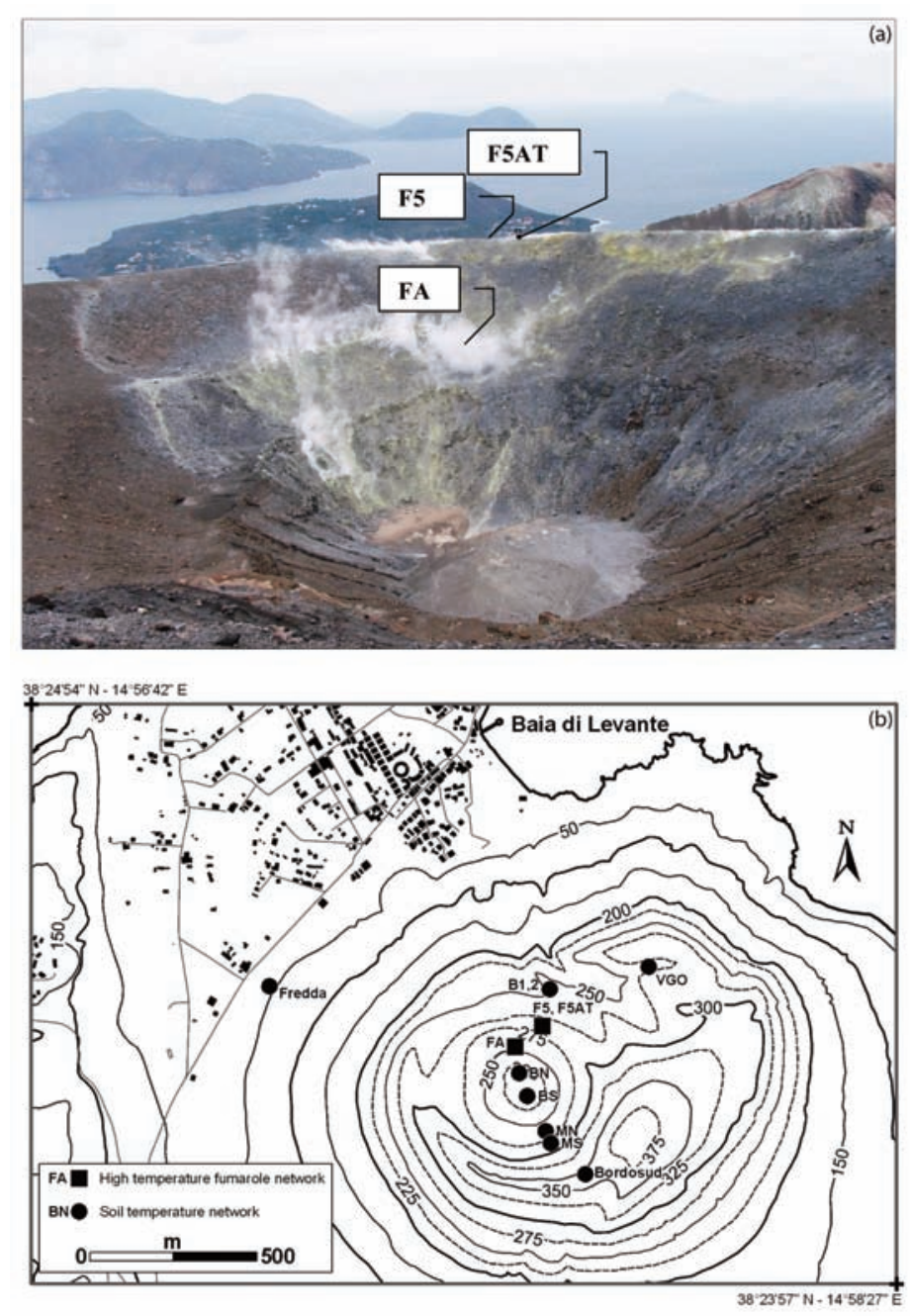

Figure 2. (a) Photograph of the fumarolic field of the La Fossa cone, taken from the southern side of the outer edge. The location of the F5AT, F5 and FA monitoring points are indicated. (b) Mapped locations of the temperature monitoring sites (with 1-h sampling rates) installed at the La Fossa cone by the Istituto Nazionale di Geofisica e Vulcanologia, sezione di Palermo. enthalpy fluids (separated by magmatic sources) and lowenthalpy fluids (separated by hydrothermal sources), the mixtures of which feed the fumaroles. Moreover, the outlet temperatures are greatly influenced on the one hand by the ascent processes of fluids from their sources to the surface [Nuccio et al. 1999], and on the other hand by exogenous factors, like atmospheric pressure, wind and rain. With the need to take into account so many variables, it is difficult to extrapolate endogenous variations just according to changes in the temperature records. However, the variations observed by long-term monitoring can offer a way to understand the deep processes affecting the system if they are interpreted as comparative evaluations with the other parameters.

Specifically, the separation of fluid phases from magmatic and hydrothermal reservoirs, and their expansion from their sources to the surroundings, are the processes invoked by geochemists to fit thermodynamic theories to volcanic dynamics. The scientific models published to date to fit the empirical data have not yet been depicted on a multidisciplinary basis that takes into account the complex relationships caused by the thermodynamic laws governing every geochemical system. For Vulcano Island, previous studies have linked the surface variations in the geophysical and geochemical parameters to active magmatism [Barberi et al. 1991, Nuccio et al. 1999] or to tectonic processes related to the dynamics of this Mediterranean region [Montalto 1996, Ventura et al. 1999, Mattia et al. 2008]. Only recently has a multidisciplinary approach been published [Cannata et al. 2011], which showed the comparison of consistent sets of data that were acquired by continuous monitoring. Some of the data from this last study are included here in more detail (see below).

\section{Measurement methods}

Since the 1980's, the crater fumaroles have been monitored by the network of the Istituto Nazionale di Geofisica e Vulcanologia, sezione di Palermo. The temperatures have been measured using thermocouples that were installed at a few fixed points. Monitoring stations for high-temperature fumaroles are dangerous to install and also problematic to maintain, because they require close approach to an area where there is copious discharge of hot and toxic fluids. Thus, the time series of the temperatures obtained show some gaps due to the temporal failure of the system. However, the attention paid to the maintenance of the monitoring system allowed us to observe the time variations of the surface temperatures at the different monitoring stations, and to follow the recent evolution of the volcanic area.

Real-time records of high-temperature fumaroles are now being carried out at the F5, F5AT and FA fumaroles. The outlet temperatures are measured by chromel-alumel thermocouples (sensitivity, ca. $41 \mathrm{IV} /{ }^{\circ} \mathrm{C}$; resolution, $0.025^{\circ} \mathrm{C}$ ), these sensors are equipped with stainless-steel probes that 
are made to resist the corrosive acidic gases. For monitoring purposes, the measuring instrument is kept away from the fumarole emissions, while the metal probe is inserted into the steaming vent to a depth of $0.5 \mathrm{~m}$, to improve the contact between the sensor and the steaming ground, and to reduce external disturbance. To take accurate measurements, the technique of cold junction compensation has been applied, and the maintenance work ensures good thermal contact between the input connectors and the measuring instrument. The cold junction compensation is provided by an electronic process that takes into account the voltage produced by the temperature variations at the cold joint. In this configuration, «cold» refers to the ambient temperature, as compared to the hot fumarole temperature. However, sometimes good thermal contact at the cold junction is lost due to the extreme weather conditions of fumarole areas, and disturbances can appear in the time series. In these cases, we recognize erroneous data by comparing the ambient temperature variations with the fumarole records, and as these disturbances can hide the real temperature variations of the fumaroles, we usually erase them from the time series until the technical personnel have been able to do the maintenance field-work.

Over these years, the sampling frequency of this continuous monitoring has changed: from 1998 to 2008 the data were sampled every $2 \mathrm{~h}$, then later on the data were acquired with at an hourly frequency and are transmitted via radio once a day to the acquisition center in Palermo. From the acquisition center, is also possible to program the acquisition, for changes to the sampling frequency and the download frequency. Episodic temperature surveys have also been carried out over the fumarolic field using noncontact infrared sensors, known as pyrometers, as well as using these chromel-alumel thermocouples. At these hightemperature fumarole vents, comparisons between the values obtained using these two different sensors show the same data, which confirms that the multiphase system is in thermal equilibrium with the pressurized steam. Thus, direct measurements made below ground level produce the same data as indirect measurements, made above the ground surface, that are based on the radiative transfer processes. The main differences between the data acquired by the direct measurement (thermocouple inserted in the vent) and by indirect measurements (non-contact infrared sensor) may occur only in cases where different targeted surfaces are compared.

\section{Temperature time series}

\subsection{External disturbances on the temperatures recorded}

The high-temperature fumaroles of the La Fossa cone are located where heavy rain quickly runs off, instead of seeping through the scoria, because they are mainly on the crest
(Figure 2, F5, F5AT) and along the inner slope (Figure 2, FA).

An example of the temperature variations that are related to rainfall events is reported in Figure 3. In autumn, some intense rainfall occurred during October 2010, and minor rainfall thereafter. Generally, the effects of intense rainfall on fumaroles is a prompt decrease in temperature, which can range from $20{ }^{\circ} \mathrm{C}$ to $40{ }^{\circ} \mathrm{C}$ across the three different points, with the background temperatures recovered in less than 2 days. However, on one occasion (October 19-20, 2010), the heavy rain fell in a very restricted area (on the active cone) and had a major effect on the fumarole temperatures. After this rainfall, the normal temperatures were recovered over 4 to 7 days. The following minor rain events caused minor disturbances to the timeseries. This period shows that a systematic method for the removal of such external effects by temperature variations is difficult to propose, because these external effects on the fumarole temperatures depend on many factors. Besides the total amount of rain, the disturbances caused by rainfall depend mainly on the surface run-off and the ambient temperature, and even more so on the steam flux. These represent too many parameters to be continuously monitored with the resources available for geochemical surveillance.

The meteorological influences on the fumarole emissions have also been analyzed at Merapi (Indonesia) [Richter et al. 2004] for fumarole temperatures ranging between $320^{\circ} \mathrm{C}$ and $400^{\circ} \mathrm{C}$. Altough the outlet temperatures are similar to those of Vulcano Island, the effects of rainfall at Merapi are hardly comparable, for various reasons. First, there are different amounts of rainfall (Merapi: $1400 \mathrm{~mm}$ of rainfall in 6 months; Vulcano: generally less than $650 \mathrm{~mm}$ of rainfall in 1 year). Then there are different sources of thermal energy that feed these two different volcanic systems: at Merapi vulcano, an active lava dome was degassing during

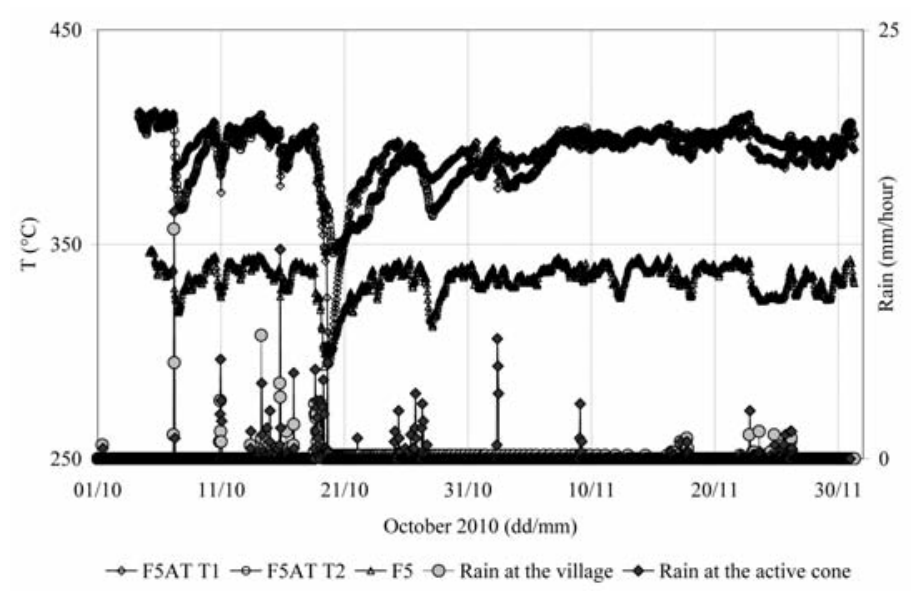

Figure 3. Short-term effects of rainfall on the fumarole temperatures. Continuous monitoring data from the fumaroles on the northern edge of the crater and rain recorded at the village of Vulcano Porto and at the top of the cone. 

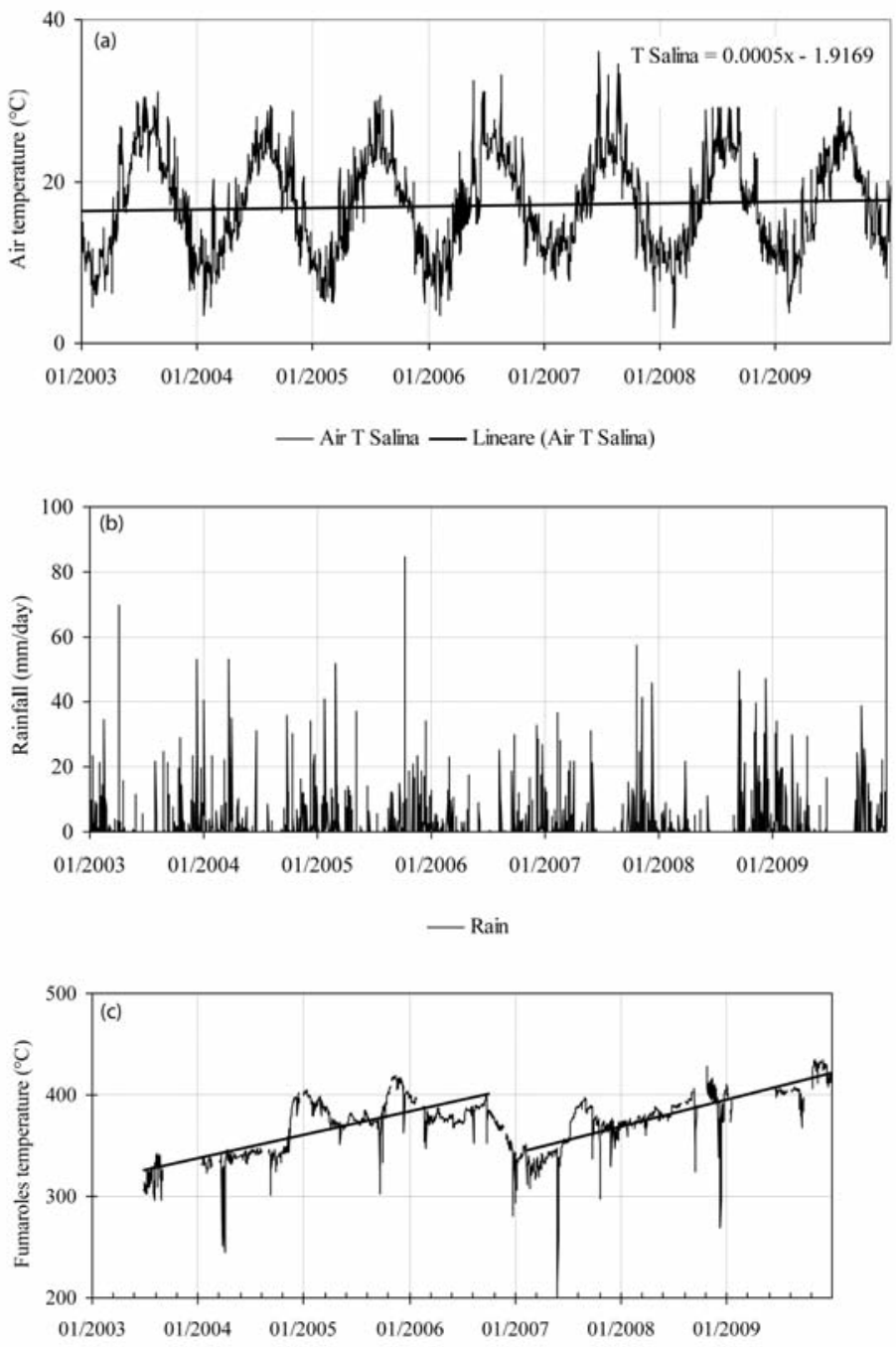

Figures 4. (a) Atmospheric temperatures recorded in the region. The linear trend calculated over 7 years is shown, with the relative equation. Data from Servizio Informativo Agrometeorologico Siciliano (SIAS, Regione Siciliana). (b) Rainfall recorded in the region from 01/01/ 2003 to 31/12/2009. Data from Servizio Informativo Agrometeorologico Siciliano (SIAS, Regione Siciliana). (c) Time-series from the continuous monitoring of the fumarole temperatures (rough data from the F5AT station). The linear trends calculated over 7 years are shown (see Figure $7 \mathrm{~b}$ for details).

the period analyzed [Richter et al. 2004], while at Vulcano, the fumaroles are fed by a hydrothermal system that receives fluids from a magmatic source. What we registered at Vulcano suggests a behavior that can be similar to Merapi only at times during short-term variations, while the meteorological impact is negligible on the mean or longterm variations of the fumaroles temperatures. Moreover, in contrast to what was observed at Merapi, at Vulcano Island no clear relationship was noted between rainfall and occurrence rate of the volcano-seismic events (VSEs) [Cannata et al. 2011]. Data from local meteorological stations sited at Vulcano Porto, and regional data published by the Servizio Informativo Agrometeorologico Siciliano (SIAS, Regione Siciliana), indicate an average of $650 \mathrm{~mm}$ of rainfall over a year in the Aeolian archipelago. Taking in consideration a set of data covering the last 7 years, most of time $(81 \%$ of the days), the amount of rain was negligible $(<1 \mathrm{~mm} /$ day) and only for $19 \%$ of the days was more rain received, reflecting a seasonal regime typical of the southern Mediterranean region.

As well as the main rainfall events, the ambient temperature variations and barometric pressure changes have also been considered in the investigation of external influences on the fumarole temperatures. Data recorded by the meteorological stations located in the region are reported in Figure 4a,b, as from January 2003 to December 2009. The ambient temperature recorded on Salina Island (an Aeolian island) show seasonal variations on a stationary trend (Figure $4 a$ ), with the rainfall also showing a stationary trend and cyclic variations (Figure $4 \mathrm{~b}$ ). Over the same period, the fumarole temperatures clearly showed increasing trends (Figure 4c), but no relationships with the ambient temperature or rainfall can be highlighted over the long term.

The atmospheric pressures recorded in this Mediterranean region show that from May to October there is a stable mean with minor variations, although the variations become more intense in the winter months. The data in Figure 5a refer to the year 2008: when the pressure data showed intense short-term variations (from January to April), the fumarole temperatures showed a stationary mean $\left(372{ }^{\circ} \mathrm{C}\right)$ with minor short-term variations. From May to October 2008, the pressures showed a stable mean with minor variations, while the fumarole temperatures increased from ca. $370{ }^{\circ} \mathrm{C}$ to more than $410{ }^{\circ} \mathrm{C}$. Then from September to December 2008 the fumarole temperatures were affected by some technical disturbances. Figure $5 \mathrm{~b}$ is a scatter diagram of the fumarole temperatures versus the atmospheric pressures, and the dispersion of these data shows that the fumarole temperature is not dependent on the pressure conditions, with both the covariance and the square correlation coefficient very low $(\mathrm{COV}=-1.54 ; \mathrm{R} 2=0.010)$.

Short-term comparisons can be discussed considering the data reported in Figure 6a, which shows the barometric pressures and the F5AT temperatures (acquired every hour) from September 9-15, 2010. The quadratic polynomials that fit these two datasets are shown. In the short term, the fumarole temperatures and barometric pressures show an inverse correlation, which was disturbed by rain events that occurred on September 10 and 11. From September 9-12, the atmospheric pressure showed a cyclic variation on a stationary trend. Over the same period, the fumarole temperatures showed a cyclic variation that was inversely related to the atmospheric pressure and was superimposed on an increasing trend. So even over this short period, the main feature observed for the fumarole temperatures was a net increase in temperature (of more than $20^{\circ} \mathrm{C}$ in 4 days). Figure $6 \mathrm{~b}$ shows the scatter diagram of the fumarole 

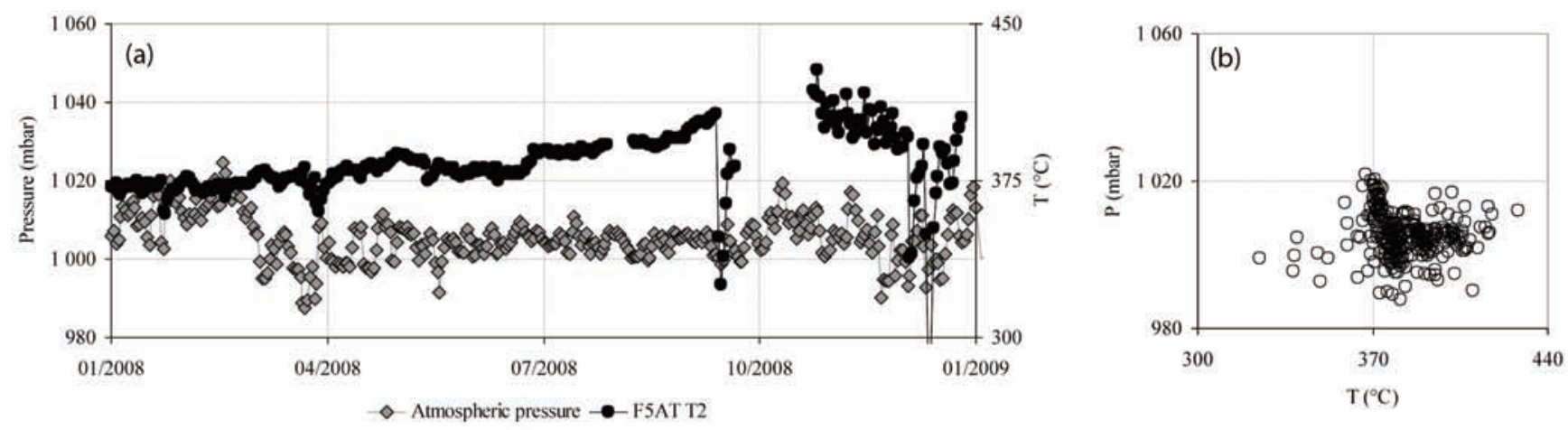

Figure 5. (a) Variations in the atmospheric pressure and the fumarole temperatures recorded over one year (2008). (b) Fumarole temperatures versus atmospheric pressures, using the data from (a).
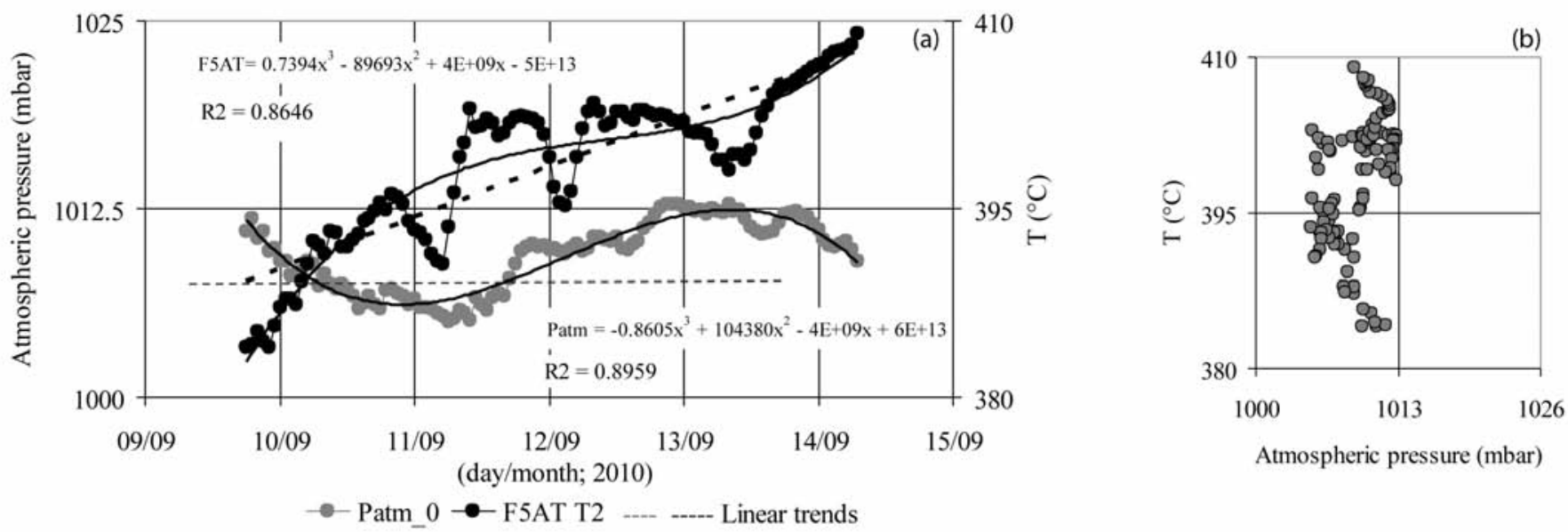

Figure 6. (a) Short-term variations recorded for atmospheric pressure and fumarole temperatures (September 9-15, 2010). The linear trends for both of the parameters are shown, as well as the best-fit polynomial curves of the third order, with the relative equations and regression coefficients. (b) Fumarole temperatures versus atmospheric pressures, using the data from (a).

temperatures versus atmospheric pressures for this period, and the dispersion of the data shows low correlation between the two variables.

To filter short-term rain effects out of data series, the days with heavy rainfall have been removed. Comparing the two temperature series (unfiltered and filtered), the main variations are unchanged (Figure 6).

At La Fossa, the cone temperatures showed short-term effects related to rain events, and negligible effects related to atmospheric temperature variations; moreover, no clear relationships have been highlighted between the fumarole temperatures and the barometric changes.

\subsection{Main variations}

The intense variations observed in the temperatures of the fumarole vents of the La Fossa cone have been variously documented. The highest value measured in the past was $670{ }^{\circ} \mathrm{C}$, which was recorded in January 1993 for the FA fumarole located on the inner flank of the La Fossa cone [Nuccio et al. 1999]. Afterwards, until March 1995, this site showed temperatures higher than $500{ }^{\circ} \mathrm{C}$, while the other fumarole vents ranged between $350^{\circ} \mathrm{C}$ and $500^{\circ} \mathrm{C}$ (database of the Istituto Nazionale di Geofisica e Vulcanologia, sezione di Palermo). After 1995, the temperatures of FA started to decrease, but the surface of active vents increased, and many new vents opened at the edge of the active cone [Bukumirovich et al. 1997, Harris and Maciejewski 2000; Pecoraino, personal communication]. Nowadays, the fumarole with the highest temperature is located on the edge of the active cone (Figure 2, F5AT), while the outlet temperature of FA, on the inner flank (Figure 2), has continued to decrease. During the summer of 2010, the temperature of F5AT fell from $430{ }^{\circ} \mathrm{C}$ to $410{ }^{\circ} \mathrm{C}$, while the temperature of $\mathrm{FA}$ was reaching its minimum value of $260^{\circ} \mathrm{C}$. It is worth noting, however, that the active exhaling area of the FA fumaroles is still growing, showing a behavior that cannot be interpreted as the result of decreasing heat flow from the underground system.

The time-series of temperatures recorded at the F5AT station from 1998 to 2009 is shown in Figure 7 and discussed here. To show a more homogeneous set of data, just the means of the recorded values have been considered for each day.

Starting from August 1998, the main characteristics of the temperature variations for $\mathrm{F} 5 \mathrm{AT}$ are the negative trend 
from August 1998 to January 2001 that was followed by a positive trend that started in December 2000 and lasting until December 2009 (Figure 7b). During this period, many temperature variations were superimposed on these trends. On the occasions of the most intense temperature increases, the local seismic activity also increased [Aubert and Alparone 2000, Alparone et al. 2010, Cannata et al. 2011].

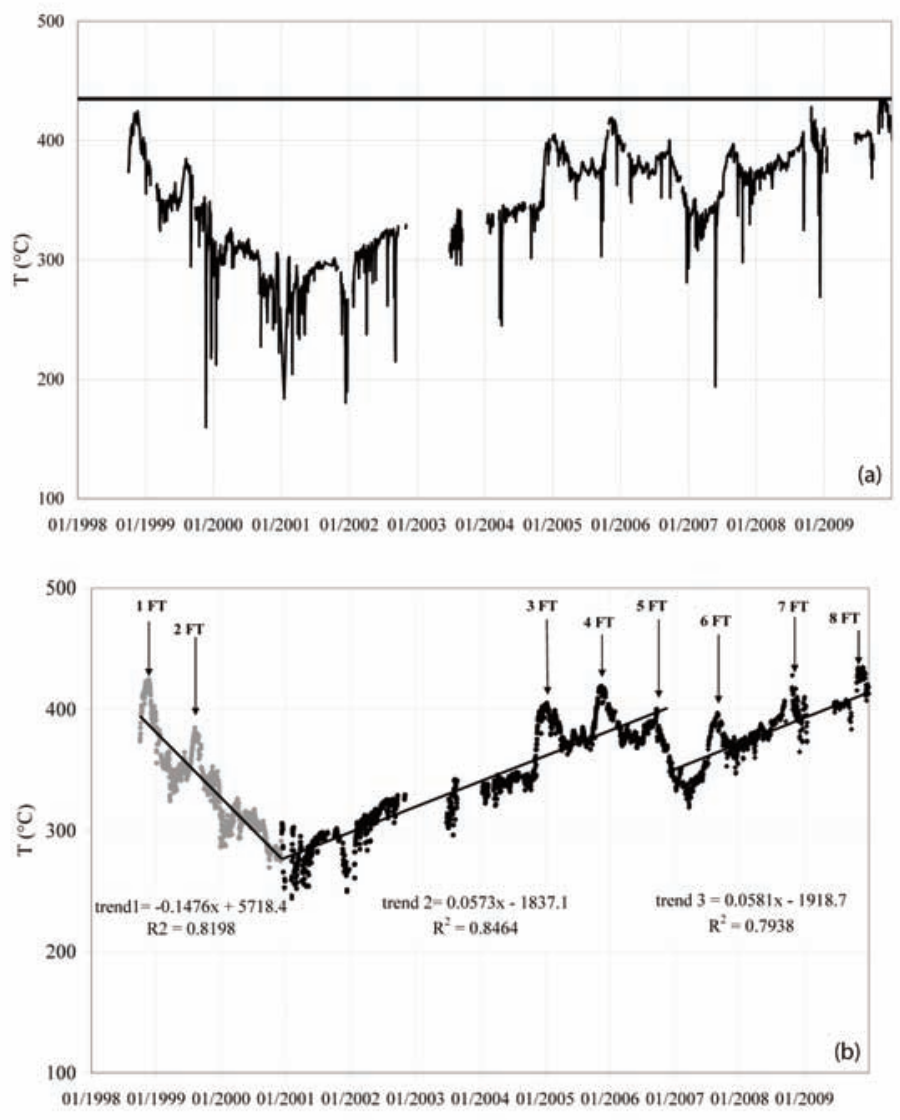

Figure 7. (a) Time-series from continuous monitoring of the fumarole temperatures, as the rough data from the F5AT station (January 1998 to December 2009). The horizonal line indicates the maximum temperature recorded over this period. (b) As for (a), after removing short-term rain effects. The equations under the linear plots correspond to the trends for the best-fits of the time variations. The peaks due to the fumarole temperature variations are labeled from 1 FT to 8 FT.
From October 1998 to November 2009, at least eight temperature variations were observed. These cyclic pulses project out of the major trends (Figure $7 \mathrm{~b}$ ) and show comparable intensities. Table 1 gives the times of occurrence, the temperatures reached by each peak, and the rates of variation. These temperature variations are discussed further below, with reference to concurrent anomalous variations recorded through different geochemical and geophysical parameters.

The first peak of temperature occurred in autumn 1998 (Figure 7b, 1 FT). During this period, many geophysical and geochemical parameters suggested an increase in the rate of energy released from the volcanic system. A general increase in temperature, which started on October 3, 1998, reached its maximum values at the beginning of November (Figure 8a). The high temperature was maintained until November 20, 1998. In this period, all of the fumaroles sampled for geochemical surveillance showed peaks of carbon dioxide content (Figure 8b; data sourced from the database of the Istituto Nazionale di Geofisica e Vulcanologia, sezione di Palermo) as well as other variations in their chemical compositions that suggested a temporary increase in the magmatic component in the fumarolic gases. From November 17 to 19,1998 , significant seismic activity was recorded at La Fossa (Table 2): «Five events, focal depths ranging 1-4 km, with seismic signals of typical faulting earthquakes, triggered by mechanism of shear fracturing were recorded» [Aubert and Alparone 2000]. Moreover the same paper shows an increase in the heat flux from the soil, occurred at the top of the La Fossa cone a couple of days after the seismic swarm.

The second peak (August 1989; Figure 7b, 2 FT) was similar to the previous one in terms of intensity and duration, but there was no evidence from other parameters relating to increases in the exhaling activity or seismic release in this period. However, both of these first two peaks (November 1998, August 1989) lay on a decreasing temperature trend that stopped in January 2001.

After a further 5 years, when the output temperature

\begin{tabular}{cccccccc}
\hline $\begin{array}{c}\text { Temperature } \\
\text { variations }\end{array}$ & $\begin{array}{c}\text { Start } \\
\text { date }\end{array}$ & $\begin{array}{c}\text { Peak } \\
\text { date }\end{array}$ & $\begin{array}{c}\text { Start } \\
\left({ }^{\circ} \mathbf{C}\right)\end{array}$ & $\begin{array}{c}\text { Peak T } \\
\left({ }^{\circ} \mathbf{C}\right)\end{array}$ & $\begin{array}{c}\text { Peak rate } \\
\left({ }^{\circ} \mathbf{C} / \text { day }\right)\end{array}$ & $\begin{array}{c}\text { Max temperature } \\
\text { variation }\left({ }^{\circ} \mathbf{C}\right)\end{array}$ & $\begin{array}{c}\text { Duration } \\
(\text { days })\end{array}$ \\
\hline 1 FT & $03 / 10 / 1998$ & $20 / 11 / 1998$ & 373 & 422 & 1.02 & 49 & 48 \\
2 FT & ND & $08 / 08 / 1999$ & 341 & 384 & ND & 43 & ND \\
3 FT & $06 / 11 / 2004$ & $13 / 01 / 2005$ & 351 & 398 & 0.69 & 47 & 68 \\
4 FT & $08 / 10 / 2005$ & $31 / 10 / 2005$ & 389 & 415 & 1.13 & 26 & 23 \\
5 FT & $10 / 07 / 2006$ & $16 / 07 / 2006$ & 372 & 387 & 2.50 & 15 & 6 \\
6 FT & $09 / 07 / 2007$ & $30 / 08 / 2007$ & 360 & 397 & 0.71 & 37 & 52 \\
7 FT & $03 / 09 / 2008$ & $26 / 10 / 2008$ & 400 & 428 & 0.53 & 28 & 53 \\
8 FT & $23 / 09 / 2009$ & $01 / 11 / 2009$ & 394 & 434 & 1.03 & 40 & 39 \\
\hline
\end{tabular}

Table 1. Temperature peaks from the fumarole vent F5AT. The peaks are labeled according to Figure $7 \mathrm{~b}$. 


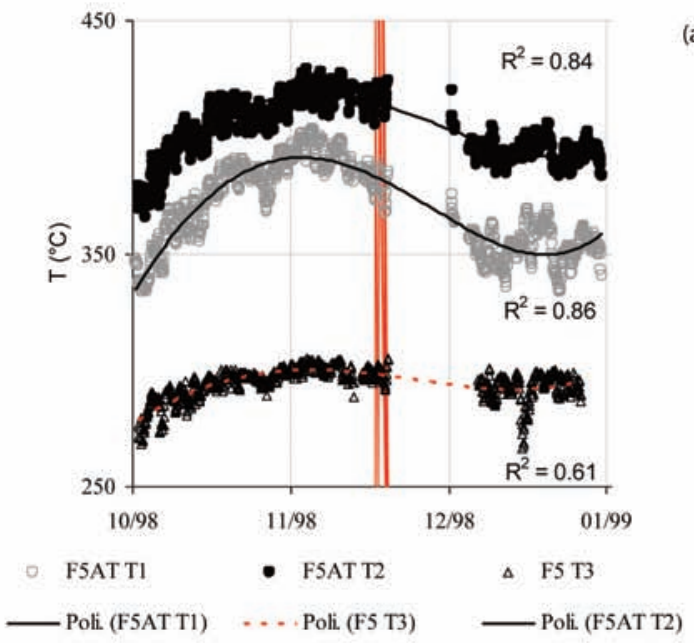

(a)

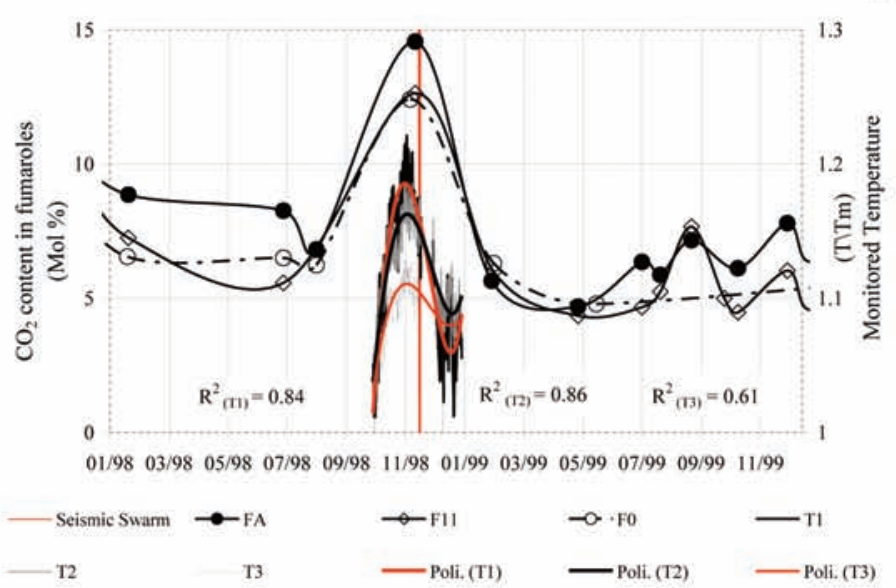

Figure 8. (a) Cyclic variations recorded at the high-temperature fumarole field from October 1998 to December 1998 (1 FT). The 3 data series come from the fumaroles located on the edge of the active cone (T1, T2, from F5AT; T3 from F5). The temperature data were recorded every $2 \mathrm{~h}$, and missing data are due to technical failures caused by the heavy rains that fell after November 20, 1998. The best-fit polynomial curves are shown, with their relative regression coefficients. Red lines, time of the faulting seismic sequence with focal depths ranging from $1 \mathrm{~km}$ to $4 \mathrm{~km}$. (see Table 2). (b) $\mathrm{CO}_{2}$ content and cyclic temperature variations (1 FT) of the fumaroles sampled at the La Fossa cone from January 1998 to November 1999. The 4th order polynomial curves which best fit the recorded data are given, with their relative square regression coefficients $\left(\mathrm{R}_{(\mathrm{T})}^{2}\right)$. The $\mathrm{T}$ values were normalized for easier comparisons according to the equations:

$$
\mathrm{T} / \mathrm{T} m=t x \div \bar{t} \text { and } \bar{t}=\sum_{1}^{n} t \div n
$$

where $\bar{t}$ represents the background reference for each monitored site, here as, respectively: $\bar{t}_{1}=360^{\circ} \mathrm{C} ; \bar{t}_{2}=380^{\circ} \mathrm{C} ; \bar{t}_{3}=270^{\circ} \mathrm{C}$.

\begin{tabular}{cccccccccc}
\hline $\mathrm{N}^{\circ}$ event & Date & Time & $M_{d}$ & Lat & Long & H & RMS & ERH & ERZ \\
\hline 1 & $17 / 11 / 1998$ & $10: 38: 24.76$ & 1.3 & 38.409 & 14.956 & 1 & 0.28 & 1.5 & 0.2 \\
2 & $18 / 11 / 1998$ & $07: 39: 45.08$ & 2.3 & 38.409 & 14.963 & 4.1 & 0.1 & 1.1 & 0.9 \\
3 & $18 / 11 / 1998$ & $15: 49: 32.08$ & 1.4 & 38.397 & 14.959 & 2.7 & 0.09 & 0.4 & 0.4 \\
4 & $19 / 11 / 1998$ & $02: 12: 54.62$ & 2.4 & 39.409 & 14.97 & 4.3 & 0.2 & 1.1 & 1.2 \\
5 & $19 / 11 / 1998$ & $05: 34: 34.20$ & 1.4 & 38.407 & 14.952 & 1.6 & 0.18 & 1.6 & 0.9 \\
\hline
\end{tabular}

Table 2. Main characteristics of the seismic swarm that occurred in November 1998 [Diliberto et al. 2007]. Md: magnitude; RMS: root mean square error of residual travel time (s); ERH: horizontal error; ERZ: vertical error; H: focal depth $(\mathrm{km})$.
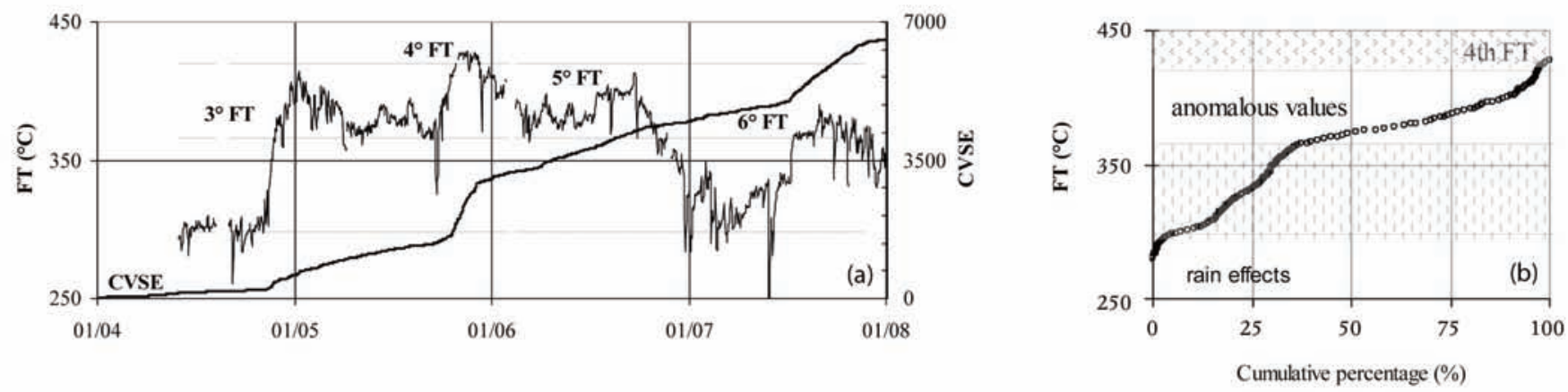

Figure 9. (a) Temperature variations of the F5AT fumarole from 2004 to 2007, and the cumulative number of volcano seismic events (CVSEs) registered at the La Fossa cone (modified from Cannata et al. 2011). The major slope changes of the CVSE occur when the fumarole temperatures increase. The 3 FT to 6 FT peaks in temperature are shown (as in Figure 7b and Table 1). Dashed lines are the threshold values for the F5AT temperatures for (b). (b) Probability plot of the fumarole temperatures and the selected thresholds between different samples of values (dashed lines): $366{ }^{\circ} \mathrm{C}$ is the limit between the two main samples interpreted as the background ( $25 \%$ of the values) and the anomalous temperatures (about $60 \%$ of the values). Fumarole temperatures $<300{ }^{\circ} \mathrm{C}$ represent background values that are generally disturbed by heavy rain (less than $8 \%$ of the data). Fumarole temperatures $>420{ }^{\circ} \mathrm{C}$ represent less than $4 \%$ of the recorded values, and occurred during the 4 FT geochemical anomaly (November 2005; see (a)). Redrawn from Cannata et al. [2011]. 
appeared to be perturbed essentially by heavy rains, a new series of temperature peaks occurred, between November 2004 and July 2006 (Figure 7b, 3 FT, 4 FT, 5 FT). Again these events coincided with other geochemical and seismic anomalies that were highlighted on their respective timeseries [Diliberto et al. 2007, Alparone et al. 2010], and that were sometimes interpreted as increases in the magmatic component in the fumarolic gases [Granieri et al. 2006].

From December 2006 to July 2007, the outlet temperature was lower than would be expected according to the positive trend started in August 2000, although afterwards the average temperatures increased again, and three new peaks were recorded up to November 2009 (Figures 7b, 6 FT, 7 FT, 8 FT). These three peaks ran parallel to the increasing temperature trend, and the last one reached an outlet temperature comparable with that of November 1998 (Figure 7b).

A general positive correlation between temperature variations, and seismic release and deformation was discussed by Cannata et al. [2011]. The results from a comparison of the fumarole temperatures and the rate of VSEs is reported here over a period when complete and comparable data were available for both time-series (August 2004 to December 2007; Figure 9a).
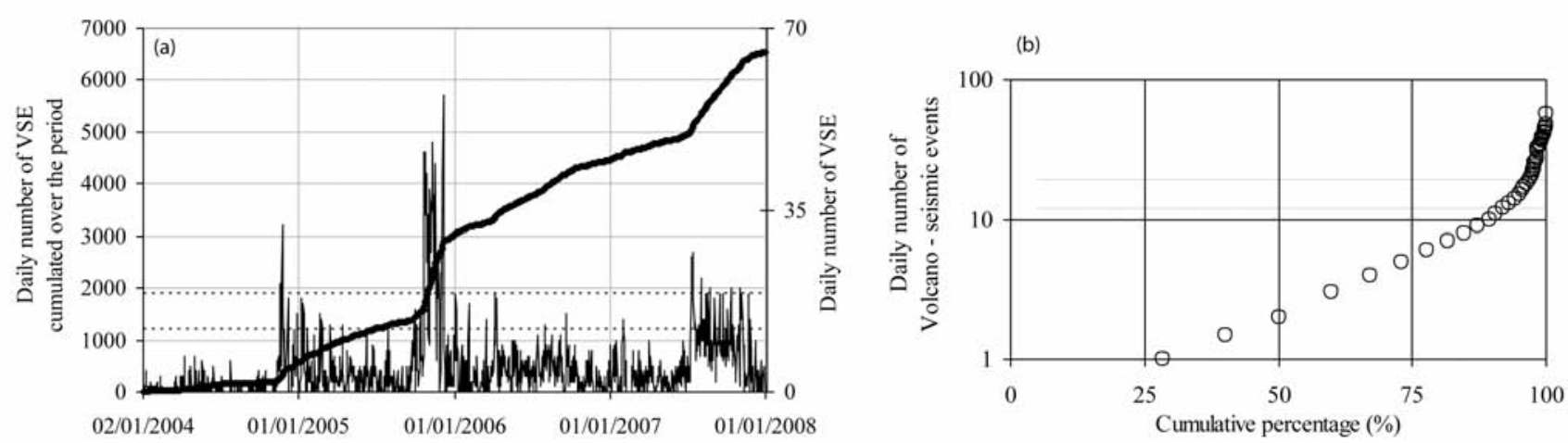

Figure 10. (a) Daily rates of VSEs recorded at Vulcano Island from 2004 to 2007 (redrawn from Cannata et al. 2011), and cumulative VSE curve (CVSE). Dashed lines, threshold values separating the background seismic rate from the anomalous seismic rates. Thresholds were chosen using the probability plot in (b). (b) Frequency distribution of the VSEs for the threshold selection of the background rates( $<12$ VSEs a day) and the anomalous rates ( $>19$ VSEs a day).
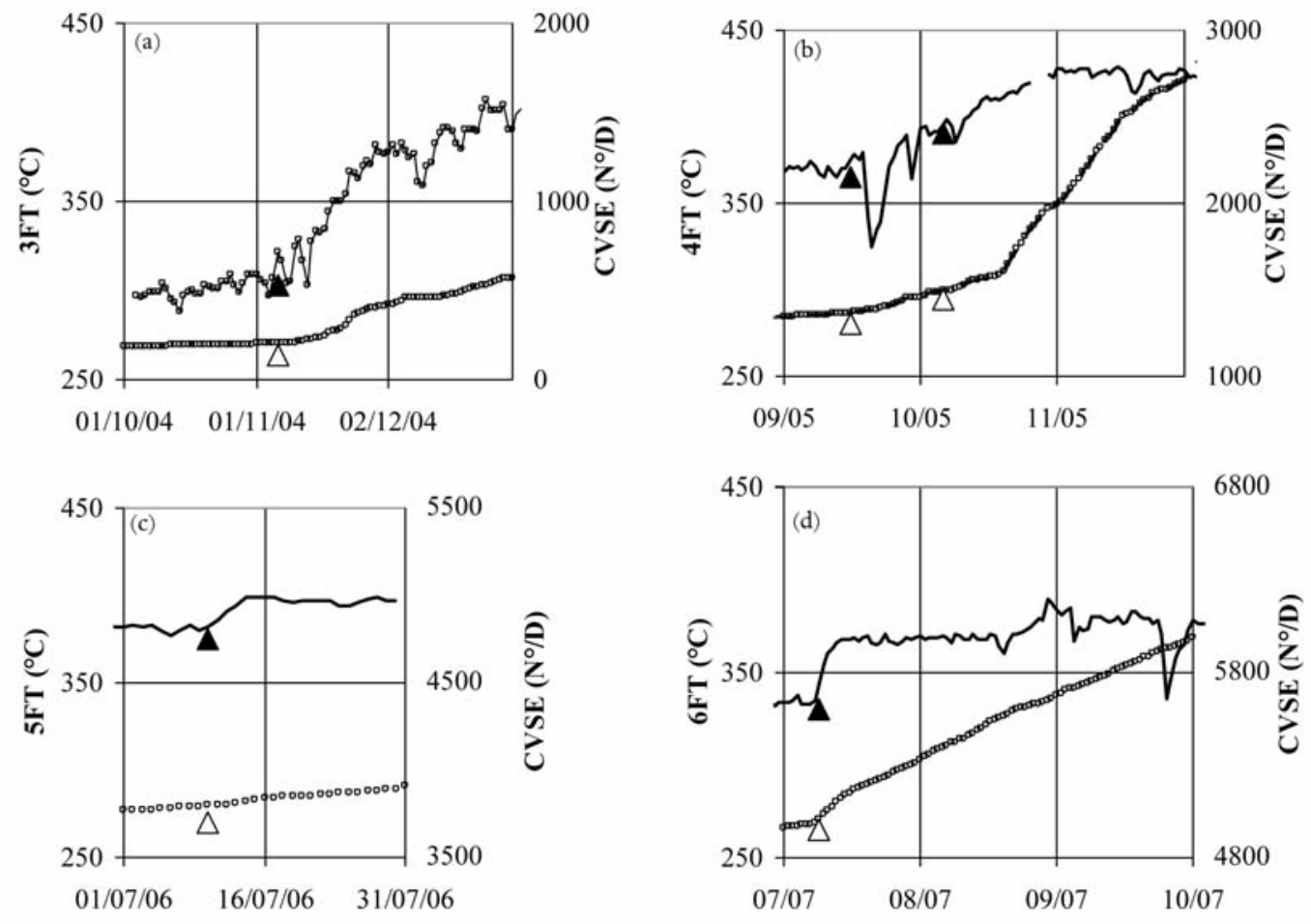

Figure 11. Details from Figure 9a for the onsets of each temperature peak. The black triangles on the temperature curves (FT) and the open triangles on the cumulative curve for the volcano-seismic events (CVSEs) indicate the starting dates for the increases in temperature. See Table 1 for dating and details. (a, b) For 3 FT and 4 FT, where the slope changes for the CVSE occur after the onset of the temperature peak. (c) For 5 FT, where no slope change is seen for the CVSE. (d) For 6 FT, where the slope change for the CVSE occurs at the same time as the fumarole temperature increases (July 2007). 
The thermal parameter is directly related to the thermal energy released (the heat flow) by the underground system, while the rate of VSEs is directly related to the local seismic energy released (work performed by the multiphase system). The high temperatures of the fumaroles and the rate of VSEs are expressions of two different energy forms, so their time variations can be somewhat different, for two reasons:

1. The heat flow is an energy form that is continuously released by the hydrothermal system at Vulcano Island, and it feeds the fumaroles as well as the thermal springs and thermal wells of Vulcano Porto Village. On the contrary, the seismic energy release is discontinuous, whereby the system needs a physical threshold to be passed before registering a VSE.

2. The upper limit of the temperature for the fumaroles can be referred to the thermodynamic conditions of the sources, while the upper limit of VSEs rate depends on the geophysical interpretations, which are beyond the scope of this study. We expect that the maximum output temperature is mainly influenced by the pressure and temperature conditions of the hydrothermal system beneath the active cone, since the fluid is the result of mixing between hydrothermal sources and the deepest magma sources.

However, the data show that from January 2004 to December 2007, there were three periods of major VSEs. In these periods, more than 14 , up to 57 , events were registered in a day (Figure 10a), with a maximum rate in November 2005. Figure 10b shows the probability plot for threshold selection between the background and the anomalous rates. During the same interval of time, the fumaroles showed four intense variations in their output temperatures (Figure 9a, 3 FT to 6 FT). These peaks of temperature corresponded to a net slope change, except for July 2006 when the VSE rate did not exceed the threshold of the anomalous release (see Figure 9a).

The correlation between the anomalous heat flux from fumaroles and the anomalous volcano-seismic release has only been focused on the data at the onset of an anomalous heat flux (Figure 11). The filled triangles plotted along the temperature curve (FT) and the open triangles plotted along the cumulative curve of VSEs (CVSEs) (Figure 11) indicate the starting dates of the increases in temperature. The anomalous periods registered by geophysical and geochemical data indicate that the heat flow and the seismic release of local origin show a direct correlation. The time lag between the onsets of the different time-series is of the order of days, and different delays are seen for each period among the fumarole temperatures and the VSEs. The crosscorrelation between the fumarole temperatures and the VSEs, as applied to the subsets of data shown in Figure 11, give a maximum squared correlation factor (R2) ranging from 0.88 to 0.97 for delays of a few days, even though they are not homogeneous. In particular, the VSEs registered variable delays with respect to the fumarole temperatures, delays lasting from ten days, as in the autumn of 2004, to zero days, as in July 2007. The sources of these VSEs were located below the La Fossa crater area, at depths of $0.5 \mathrm{~km}$ to $1.1 \mathrm{~km}$ [Alparone et al. 2010]. The small delays observed from 2004 to 2007 suggest that the dynamics of the hydrothermal fluids are the cause of most of the VSEs [Cannata et al. 2011].

\section{Conclusions}

Gas flux, composition and temperature have been routinely and sometimes continuously determined at active fumarole fields. These parameters have allowed geochemical evaluations of the hydrothermal systems and the interpretation of the changes observed [Barberi et al. 1991, Tedesco 1995, Bukumirovich et al. 1997, Nuccio et al. 1999, Nuccio and Paonita 2001, Di Liberto et al. 2002, Aubert et al. 2008].

During a period of quiescent activity, the steam released through fumarolic fields is an important component in the energy balance of volcanic systems. While steam flow measurements are not yet available for long-term monitoring, continuous monitoring of fumarole temperatures accounts for the evolution of exhaling activity and contributes to the evaluation of the risk level associated with this.

Results from thermal monitoring of fumarolic fields indicate that the thermo-physical properties of the hydrothermal systems actually feeding the active cone are not stable and are subjected to frequent departures from stationary regimes.

In the fumarole area of the La Fossa cone, external agents, such as rain and barometric perturbations, have only minor influences and short-term effects on the fumarole temperatures. The main characters of variations observed for a fumarole located on the northern edge of the active cone was a trend for decreasing temperature that was interrupted at the end of 2000 , to be followed by new trends of increasing temperatures, which were still active during 2009. Some cyclic pulses are superimposed on these trends (Figure $7 \mathrm{~b}$ ). These cyclic pulses were observed over eight periods, starting from October 1998 to November 2009.

Temperature cycles have been often associated with coherent changes in the molar fraction of $\mathrm{CO}_{2}$ in fumaroles [Aubert et al. 2008, Alparone et al. 2010; Paonita, personal communication]. The geochemical interpretation of the observed time relationships is that the continuous monitoring of high-temperature fumaroles can reveal increased enthalpy input from a deep magmatic source to the brine-type biphasic hydrothermal system located between $1 \mathrm{~km}$ and $2 \mathrm{~km}$ in depth [Chiodini et al. 1995, Nuccio et al. 1999, Di Liberto et al. 2002]. Moreover, the direct correlation observed between the time-series of temperature and seismic release indicates that both parameters give expression to the internal forces acting on 
the geodynamic system of Southern Thyrrenium. In particular, the surface thermal variations reveal changes in the heat flow from the underground system, while the rate of VSEs reveals the work performed by the multiphase system, probably as a local response to the regional geodynamics.

By paying attention to a parameter directly related to the heat flow (like the maximum temperature of fumaroles), we have been able to follow the active system during periods of fumarolic activity, when the evolution of the equilibrium can be revealed only by instrumental systems. Further investigations are necessary for modeling the effective behavior of the natural system and they will be aimed at defining any relationships with other energy forms released by the underground system, like the seismic activity and mass flow. The exchange of the acquired data among different scientific disciplines involved in surveillance, coupled to long-term comparisons, will be necessary to have the surveillance programs working properly and to obtain reductions to the cost-benefit ratio.

Acknowledgements. The seismic data compared to the fumarole temperatures were provided by the Istituto Nazionale di Geofisica e Vulcanologia, sezione di Catania, and were published in Cannata et al. [2011]. I am grateful to Marcello Liotta, who has been supplying data since 1998, and to the technical staff of Istituto Nazionale di Geofisica e Vulcanologia, sezione di Palermo, for the field-work and the technical solutions adopted along the way. Moreover, I thank Antonio Paonita for scientific support and helpful discussions.

\section{References}

Alparone, S., A. Cannata, S. Gambino, S. Gresta, V. Milluzzo and P. Montalto (2010). Time-space variation of the volcano-seismic events at La Fossa (Vulcano, Aeolian Islands, Italy): new insights into seismic sources in a hydrothermal system, Bull. Volcanol., 72, 803-816.

Aubert, M. and S. Alparone (2000). Hydrothermal convective flux variation related to a seismo-tectonic crisis in the Fossa of Vulcano (Italy), C.R. Geoscience, 330, 603-610.

Aubert, M., S. Diliberto, A. Finizola and Y. Chebli (2008). Double origin of hydrothermal convective flux variations in the Fossa of Vulcano (Italy), Bull. Volcanol., 70, 743-751.

Badalamenti, B., S. Falsaperla, G. Neri, P.M. Nuccio and M. Valenza (1986). Confronto preliminare tra dati sismici e geochimica nell'area di Lipari, Vulcano Bollettino GNV 1986, 37-47.

Barberi, F., G. Neri, M. Valenza and L. Villari (1991). 19871990 unrest at Vulcano, Acta Vulcanol., 1, 95-105.

Bukumirovich, T., F. Italiano and P.M. Nuccio (1997). The evolution of a dynamic geological system: the support of a GISfor geochemical measurements at the fumarole field of Vulcano, Italy, J. Volcanol. Geotherm. Res., 79, 253-263.

Cannata, A., I.S. Diliberto, S. Alparone, S. Gambino, S.
Gresta, M. Liotta, P. Madonia, V. Milluzzo, M. Aliotta and P. Montalto (2011). Multiparametric approach in investigating hydrothermal systems: The case of study of Vulcano (Aeolian Islands, Italy), Pure Appl. Geophys.; doi: 10.1007/s00024-011-0297-z.

Chiodini, G., R. Cioni, L. Marini and C. Panichi (1995). Origin of the fumarolic fluids of Vulcano Island, Italy and implications for volcanic surveillance, Bull. Volcanol., 57, 99-110.

Connor, C.B., B.M. Clement,X.D. Song, S.B. Laue and J. West-Thomas (1993). Continuous monitoring of hightemperature fumaroles on an active lava dome, Volcan Colima, Mexico: evidence of mass flow variation in response to atmospheric forcing, J. Geophys. Res., 98, 19713-19722.

Di Liberto, V., P.M. Nuccio A. and Paonita (2002). Genesis of chlorine and sulphur in fumarolic emissions at Vulcano Island (Italy): assessment of $\mathrm{pH}$ and redox conditions in the hydrothermal system, J. Volcanol. Geotherm. Res., 116, 137-150.

Diliberto, I.S., S. Alparone, M. Liotta and P. Madonia (2007). Relationship between surface temperatures and seismic activity at Vulcano (Eolian Islands), Geophys. Res. Abstr., 9, 08553.

Granieri, D., M.L. Carapezza, G. Chiodini, R. Avino, S. Caliro, M. Ranaldi, T. Ricci and L. Tarchini (2006). Correlated increase in $\mathrm{CO}_{2}$ fumarolic content and diffuse emission from La Fossa crater (Vulcano, Italy): Evidence of volcanic unrest or increasing gas release from a stationary deep magma body?, Geophys. Res. Lett., 33, L13316; doi: 10.1029/2006GL026460.

Harris, A.J.L., L. Lodato, J. Dehn and L. Spampinato (2009). Thermal characterization of the Vulcano fumarole field, Bull. Volcanol., 71, 441-458.

Mattia, M., M. Palano, V. Bruno, F. Cannavò, A. Bonaccorso and S. Gresta (2008). Tectonic features of the Lipari-Vulcano complex (Aeolian archipelago, Italy) from 10 years (1996-2006) of GPS data, Terra Nova, 20, 370-377.

Montalto, A. (1996). Signs of potential renewal of eruptive activity at La Fossa (Vulcano, Aeolian Islands), Bull. Volcanol., 57, 483-492.

Nuccio, P.M., A. Paonita and F. Sortino (1999). Geochemical mixing between magmatic and hydrothermal gases: the case of Vulcano Island, Italy, Earth and planetary Science letters, 167, 321-333.

Nuccio, P.M. and A. Paonita (2001). Magmatic degassing of multi-component vapors and assessment of magma depth: application to Vulcano Island (Italy), Earth Planet. Sci. Lett., 193, 467-481.

Richter, G., J. Wassermann, M. Zimmerb an M. Ohrnbergera (2004). Correlation of seismic activity and fumarole temperature at the Mt. Merapi volcano (Indonesia) in 2000, Journal of Volcanology and Geothermal Rese- 
arch, 135, 331-342.

Tedesco, D. (1995). Fluid geochemistry at Vulcano Island: A change in the volcanic regime or continuous fluctuation in the mixing of different systems?, J. Geoph. Reas., 100 (B3), 4157-4167.

Ventura, G., G. Vilardo, G. Milano and N.A. Pino (1999). Relationships among crustal structure, volcanism and strike-slip tectonics in the Lipari-Vulcano volcanic complex (Aeolian Islands, Southern Tyrrhenian Sea, Italy), Phys. Earth Planet. Inter., 116, 31-52.

^Corresponding author: Iole Serena Diliberto,

Istituto Nazionale di Geofisica e Vulcanologia, sezione di Palermo,

Palermo, Italy; email: s.diliberto@pa.ingv.it.

(C) 2011 by the Istituto Nazionale di Geofisica e Vulcanologia. All rights reserved. 